\title{
Prospective evaluation of prognostic value of morphometry in patients with primary breast cancer
}

\author{
J C VAN DER LINDEN, ${ }^{*} \dagger$ J P A BAAK, $\dagger$ J LINDEMAN, ${ }^{*}$ J HERMANS, \\ C J L M MEYER†
}

From the *Department of Pathology, Stichting Samenwerking Delftse Ziekenhuizen (SSDZ), the †Pathological Institute, Free University Hospital, and the $\ddagger$ Department of Medical Statistics, State University, Leiden, The Netherlands

SUMMARY In a prospective study the predictive value of a multivariate morphometric prognostic index was evaluated in 195 patients with primary breast cancer who had not been treated with any form of chemotherapy or hormonal treatment. The presence or absence of distant tumour recurrence combined with the scores of the prognostic index were compared with the survival curves predicted in a previous study. The value of the presence of lymph node metastases, number of positive nodes, tumour size, mitotic activity index, and oestrogen receptor status in prediction of prognosis were also investigated.

In agreement with the results of the previous retrospective study, the prospective use of the index had the strongest predictive prognostic value, followed by the mitotic activity index. Statistical analysis showed that the actual prognoses of 43 of the 195 patients $(22 \%)$ were more accurately determined by the prognostic index rather than by using the presence of the lymph node metastases as the classifying variable.

The prognostic index is consistently reproducible by different technicians; it is a reliable method of predicting distant recurrence of tumour and hence the prognosis of patients with primary breast carcinoma. It provides more prognostic information than the presence of lymph node metastases alone, and the index should be incorporated in routine pathology reports.

Several clinical trials have suggested that adjuvant systemic treatment in addition to radiotherapy diminishes the mortality of patients with primary breast cancer. ${ }^{1-3}$ Complete cure, however, has not yet been achieved. This is partly due to the fact that the administration of adjuvant treatment is mainly based on the finding of lymph node metastases considered at this time to be the best guide to prognosis. ${ }^{45}$ The use of this prognosticator has been criticised, for either undertreatment or overtreatment can result, ${ }^{6}$ and this may have negatively biased the results of the above mentioned studies. Consequently, many attempts have been made to identify better prognostic factors to select those patients who require or who will especially benefit from adjuvant treatment. ${ }^{6-9}$

The oestrogen receptor content has been regarded as an independent prognostic factor, ${ }^{1011}$ but recently this has been questioned. ${ }^{12-14}$ It seems that if

Accepted for publication 24 July 1986 patients with oestrogen receptor positive tumours develop distant metastases they do so later than patients with oestrogen receptor negative tumours, but that the prognosis in the end is the same in both groups of patients.

In a previous paper 271 patients with primary ductal breast cancer were investigated retrospectively. ${ }^{15}$ The mitotic activity index was the strongest single prognostic factor. Survival analysis with Cox's regression model pointed to three features: the mitotic activity index, tumour size, and the lymph node status (whether or not there was metastatic tumour spread). The combination of these three features in a multivariate assessed prognostic index was the strongest indicator of prognosis. In terms of five year survival the prognostic index compared with lymph node status alone provided more accurate information for $20 \%$ of the patients.

The above mentioned results were obtained in a research setting on retrospective material, and it was 
questionable whether routine application would provide similarly good results. In 1980 , therefore, a prospective routine study was started on entirely different patients. Furthermore, the validity of the prognostic index was investigated to predict the likelihood of distant recurrence.

\section{Material and methods}

\section{PATIENTS}

The patients included in this study were presented to the hospitals affiliated with the pathology laboratory of the Stichting Samenwerking Delftse Ziekenhuizen between July 11980 and December 31 1983. All patients had undergone surgery for primary breast carcinoma $\left(T_{\times} N_{x} M_{0}\right)$ of the "not otherwise specified" ductal type ${ }^{16}$; they were not known to have had other overt disease at the time. Eighteen patients with inadequate follow up were excluded. Of the original 261 patients initially considered, $243(93 \%)$ were available for assessment. In addition, 34 patients who had received adjuvant chemotherapy $(n=24)$ or hormonal treatment $(n=10)$, or both, and 14 patients presenting with local recurrence during the follow up period were excluded from statistical analysis. The mean age of the remaining 195 patients was 60 years (median 60, range 29-87); the mean tumour size was $2.6 \mathrm{~cm}$ (median $2.0 \mathrm{~cm}$, range $0.4-15 \mathrm{~cm}$ ). One hundred and nineteen patients had no lymph node metastases and 76 had lymph node metastases. These data fell in the same range as described in other larger series $^{1718}$ so the material can be regarded as representative. As in the retrospective study, ${ }^{15}$ patients with axillary lymph node metastases or centrally located tumours, or both, were treated with local and regional radiotherapy. The minimum follow up time was 13 months (maximum 57 months, mean 32 months).

\section{ASSESSMENT OF RECURRENCE}

In accordance with the World Health Organisation recommendations $^{19}$ recurrence of disease (reappearance of known lesions or development of new lesions) was accepted if microscopically confirmed, or if a combination of clinical, radiological, scintigraphic and biochemical data were conclusive. Only distant metastases were regarded as "recurrence".

Local recurrence (defined as recurrence of the tumour in the same breast, the axillary adipose tissue, or the overlying skin, or a tumour of the other breast) occurred in 14 patients. To preclude any dispute as to whether local recurrence should be considered as a true recurrence or as a treatment failure these 14 patients were excluded from further statistical evaluations.

\section{PATHOLOGICAL FEATURES}

The size of the primary tumour (the maximum diameter on pathological examination) was recorded. Samples of the primary breast tumour were taken for microscopical analysis (including morphometry) and oestrogen receptor content analysis. The axillary adipose tissue was extensively sampled, and blocks of the primary tumour and all of the available lymph nodes were fixed for 24-48 hours in 4\% buffered formalin and subsequently embedded in paraplast. Every effort was made to include the periphery of the primary tumour in the section. Representative tissue sections ( $4 \mu \mathrm{m}$ thick) were stained with haematoxylin and eosin. The tumours were classified according to the WHO classification - that is, ductal, lobular, medullary and others. ${ }^{16}$

\section{MOR PHOMETRIC METHODS}

Details of morphometry and theoretical background have been described elsewhere, ${ }^{20-23}$ and for their application to breast cancer the reader is referred to earlier publications, ${ }^{92-26}$ especially to one retrospective study, ${ }^{15}$ where the method is described comprehensively. Briefly, morphometry was performed on standard haematoxylin and eosin stained paraffin sections which included the centre and the periphery of the tumour. The multivariate prognostic index ${ }^{15}$ takes the following form: $\mathrm{MPi}=0.3341 \times$ the square root of the mitotic activity index; $+0.2342 \times$ the tumour size in centimetres; $-0.7654 \times$ the lymph node status (negative $=2$, positive $=1$ ).

\section{OESTROGEN RECEPTOR CONTENT}

To determine the oestrogen receptor content of the primary tumour the biochemical assay, as described by the EORTC Breast Cancer Cooperative Group, was used. ${ }^{27}$ Values of $11 \mathrm{fmol} / \mathrm{g}$ protein and above were regarded as positive and those below $11 \mathrm{fmol} / \mathrm{g}$ protein as negative. Of the 195 patients studied, assessment of oestrogen receptor was possible in 122 patients (in 63 patients not enough material was present or the material was inappropriate for sampling). Of these, 83 were oestrogen receptor positive and 37 oestrogen receptor negative. The results on two patients were borderline.

\section{STATISTICAL ANALYSIS}

All the analyses were computed using the BMDP package (sections P2D, P4F, and P1L). ${ }^{28}$ Detailed data description, including frequency distribution, minimum, mean, median and maximum, per cent and cumulative per cent were computed for all features. The actuarial recurrence rates of different values of each feature were computed using Kaplan-Meier survival curves. For continuous features, all the patients were dichotomised in numbers proportional to the 
Table 1 Contingency tables with distant recurrence as dependent variable of prognostic index, lymph node status, tumour size and mitotoc activity index (figures in parentheses are numbers per cent)

\begin{tabular}{|c|c|c|c|}
\hline & \multicolumn{3}{|c|}{ Distant recurrence } \\
\hline & Yes & No & Total \\
\hline $\begin{array}{l}\text { Prognostic index }<0.60 \\
\text { Prognostic index }>=0.60\end{array}$ & $\begin{array}{l}10(8) \\
27(37)\end{array}$ & $\begin{array}{r}112(92) \\
46(63)\end{array}$ & $\begin{array}{r}122 \\
73\end{array}$ \\
\hline $\begin{array}{l}\text { Lymph node negative } \\
\text { Lymph node positive }\end{array}$ & $\begin{array}{l}15(13) \\
22(29)\end{array}$ & $\begin{array}{r}104(87) \\
54(71)\end{array}$ & $\begin{array}{r}119 \\
76\end{array}$ \\
\hline $\begin{array}{l}\text { Tumour size }=<2 \mathrm{~cm} \\
\text { Tumour size }>2 \mathrm{~cm}\end{array}$ & $\begin{array}{l}13(13) \\
24(26)\end{array}$ & $\begin{array}{l}91(87) \\
67(74)\end{array}$ & $\begin{array}{r}104 \\
91\end{array}$ \\
\hline $\begin{array}{l}\text { Mitotic activity index }<9 \\
\text { Mitotic activity index }>=9\end{array}$ & $\begin{array}{l}10(9) \\
27(32)\end{array}$ & $\begin{array}{r}101(81) \\
57(68)\end{array}$ & $\begin{array}{r}111 \\
84\end{array}$ \\
\hline
\end{tabular}

number of patients with negative or positive lymph nodes, or subdivided further using the same criteria as described previously. ${ }^{15}$ The proportional size of the subgroups for each feature was similar to those found in the earlier study ${ }^{15}$ : these were therefore adopted.

Differences between the curves were analysed using the Mantel-Cox test. $P$ values below 0.05 were regarded as significant.

\section{Results}

The prognostic index score ranged from -1.5 to 3.6 $($ mean $=0 \cdot 4)$. Patients with a low score $(<0.6)$ had a better prognosis than patients with a higher $(\geqslant 0.60)$ prognostic index score. As the prognosis is a function of the prognostic index, the lymph node status, tumour size, and the mitotic activity index, contingency

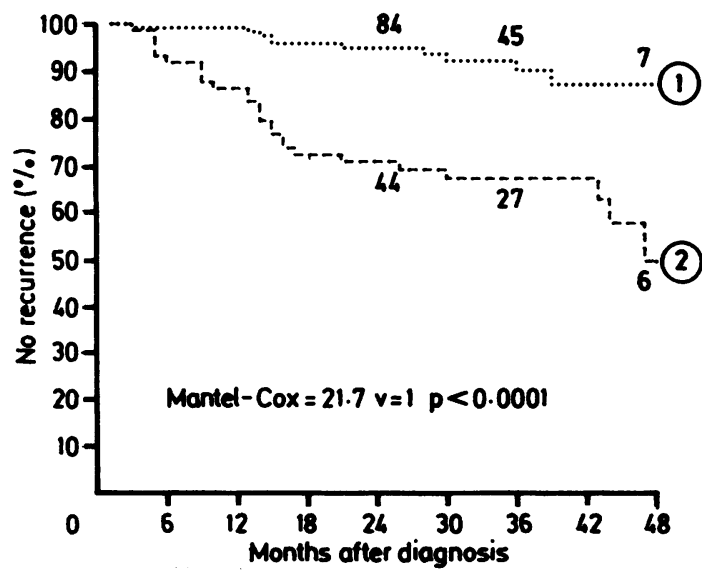

Fig 1 Kaplan-Meier recurrence free curves with prognostic index dichotomised (cut off point is 0.60).

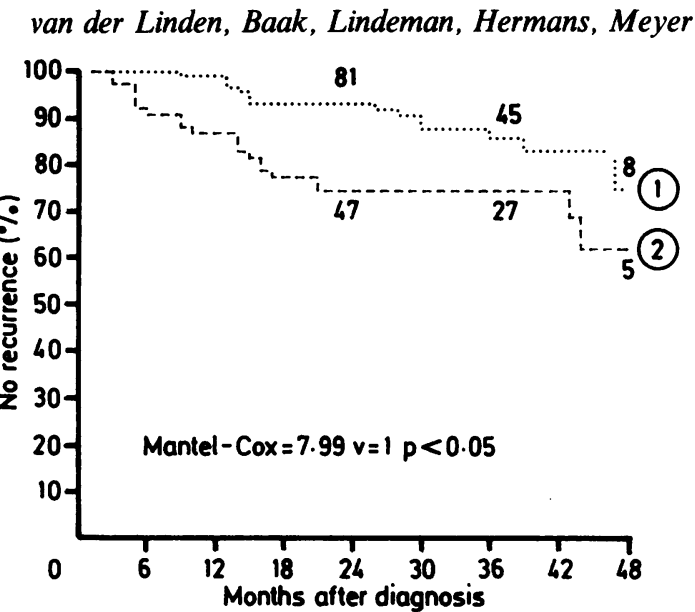

Fig 2 Recurrence free curves of lymph node negative $(n=119)$ and lymph node positive $(n=76)$ patients with breast cancer.

tables of the prognosis and these four features are given (table 1).

Fig 1 shows the dichotomised prognostic index. After 48 months of follow up the actuarial recurrencefree rate was $88 \%$ in patients with a low prognostic index $(n=122)$ and $50 \%$ in patients $(n=73)$ with a high prognostic index (Mantel-Cox test, $p<0.001$ ). This result is better than the use of lymph node status as the only prognostic feature: fig 2 shows that the actuarial recurrence free rate of the lymph node negative patients $(n=119)$ and positive patients $(n=76)$ was $80 \%$ and $62 \%$, respectively (Mantel-Cox test, $\mathrm{p}<0.05$ ).

Fig 3 shows the Kaplan-Meier recurrence free curve of the mitotic activity index. The mitotic activity index once again was the best single prognosticator.

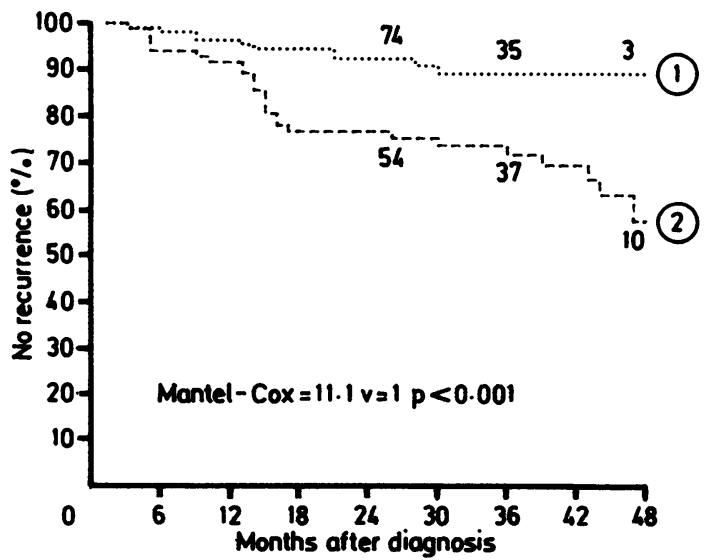

Fig 3 Recurrence free curves with mitotic activity index dichotomised (cut off point $=9$ mitoses $/ 10$ high power field). 
Table 2 Contingency table with distant recurrence as dependent variable of prognostic index and lymph node status*

\begin{tabular}{lllcc}
\hline \multirow{2}{*}{$\begin{array}{l}\text { Prognostic } \\
\text { index }\end{array}$} & $\begin{array}{l}\text { Lymph node } \\
\text { status }\end{array}$ & \multicolumn{4}{l}{ Distant recurrence } \\
\cline { 3 - 5 } & Yes & No & Total \\
\hline$<0.60$ & $(-)$ & 8 & 91 & 99 \\
$<0.60$ & $(+)$ & 2 & 21 & 23 \\
$>=0.60$ & $(-)$ & 7 & 13 & 20 \\
$>=0.60$ & $(+)$ & 20 & 33 & 53 \\
Total & & 37 & 158 & 195 \\
\hline
\end{tabular}

*Note the $(20+23=) 43$ patients for which the lymph node status and the prognostic index indicate a different prognosis.

To illustrate the power of the prognostic index compared with that of the lymph node status the 195 patients were analysed in four groups: (A) low prognostic index and lymph node negativity; (B) low prognostic index and lymph node positivity (C) high prognostic index and lymph node negativity and (D) high prognostic index and lymph node positivity. Groups A and D included most of the patients. The patients in groups $B$ and $C$ were the most interesting, however, because these groups determined the power of either the prognostic index or the lymph node status.

Table 2 shows that only two of the 23 lymph node positive patients with a low prognostic index $(8 \cdot 7 \%)$ developed a recurrence, a percentage similar to that in low prognostic index, lymph node negative patients (eight of 99 or $8.1 \%$, Mantel-Cox test, $p=0.77$ ). The same is true for patients with either lymph node negativity and positivity and a high prognostic index score (seven of 20 or $35 \%$, and 20 of 53 or $38 \%$, respectively, Mantel-Cox test, $\mathrm{p}=0.85$ ). The prognos-

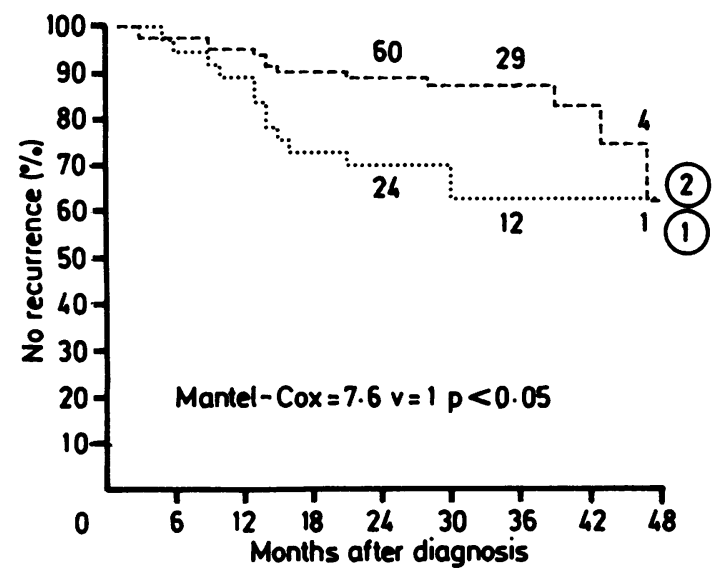

Fig 4 Recurrence free curves of oestrogen receptor negative (1) $(n=37)$ and positive $(n=83)$ patients. tic index was a more powerful prognosticator than the lymph node status and gave better information on patients' prognosis in $43(22 \%$ of all 195$)$ patients.

Fig 4 shows the Kaplan-Meier curves of the oestrogen receptor positive and negative tumours. The prognostic importance of this factor was unquestionably not as good as that of the prognostic index.

\section{Discussion}

In a previous study using multivariate analysis it was found that the combination of the mitotic activity index, the lymph node status, and the size of the tumour had a much stronger prognostic value than lymph node status alone. ${ }^{15}$

Using the Jackknife method, the predictive value of the prognostic index in a set of patients can be simulated. As such, an internal control is not the best statistical technique for evaluating the predictive value of a rule; in this study the prognostic power of the index was evaluated on a totally new group of patients, and a high prognostic value of the index was found.

One of the main differences between this and the previous study is that in this study recurrence rather than survival was taken as the dependent variable. This was done for two reasons: firstly, the follow up was relatively short and results could be obtained after a shorter period of time; and secondly, recurrence of disease is commonly used as an indication to begin further treatment, and it is therefore necessary to know whether the prognostic index is a useful method of predicting distant recurrence. The results indicate that the prognostic index is, indeed, an accurate predictor of distant recurrence and a better prognosticator than the lymph node status or any of the other investigated prognostic factors.

Of special interest are the 43 patients who had either a low prognostic index and lymph node metastases or a high prognostic index without lymph node metastases, as these subgroups most effectively show the benefit of the prognostic index. These patients would have been classified as having a good or poor prognosis using lymph node status, but using the prognostic index score the classification would have correlated much more closely with actual outcome.

Two additional facts support the value of the prognostic index as a reliable and reproducible method. In the present study absolute "blind" determination of the prognostic index was ascertained because the study was prospective and assessed routinely. The assessments were performed over three and a half years by seven different technicians, and this procedure undoubtedly has introduced some interobserver variation. Nevertheless, the predictive value of the prognostic index was similar to that obtained in the 
retrospective study, ${ }^{15}$ and this indicates that routine assessment of the prognostic index is reproducible and is, indeed, of high prognostic value.

Earlier publications have suggested that the oestrogen receptor content is an independent prognostic factor. ${ }^{1011}$ As discussed in other more recent studies, however, ${ }^{12-14}$ in the long term the prognostic difference between oestrogen receptor positive and negative tumours decreases. In this study a similar pattern was found, supporting the finding that there was no prognostic importance in long term follow up (fig 4).

In spite of the considerable gain in prognostic accuracy $(22 \%)$ a $100 \%$ prediction was not obtained, and further studies are necessary to gain more information on the cell biology of breast tumours. To conclude, the prognostic index is an inexpensive and readily assessable indicator of the prognosis of individual patients with primary breast cancer. Because only standard haematoxilin and eosin tissue sections are necessary, this technique can be incorporated as a routine procedure in most pathology institutes.

This study was financed by grant $28-735$ from Praeventiefonds.

\section{References}

1 Bonadona G, Brusamolino E, Valagussa P, et al. Combination chemotherapy as an adjuvant treatment in operable breast cancer. N Engl J Med 1976;294:405-10.

2 Fisher B, Glass A, Redmond C, et al. 1-Phenylalanine mustard (1-PAM) in the management of primary breast cancer. Cancer 1977;39(suppl):2883-903.

2 Rubens RD, Hayward JL. Estrogen receptors and response to endocrine therapy and cytotoxic chemotherapy in advanced breast cancer. Cancer 1980;46:2922-4

4 Fisher ER, Sass R, Fisher B. Pathologic findings from the national surgical adjuvant project for breast cancers (protocol No 4). Cancer 1984;53:712-23.

5 Henderson IC, Canellos GP. Cancer of the breast. The past decade. $N$ Engl J Med 1980;103:17-20, 78-90.

6 Stenkvist B, Bengtson E, Dahlqvist B, et al. Predicting breast cancer recurrence. Cancer 1982;50:2884-93.

7 Sharkey FE, Pavlak RJ, Greizer AS. Morphometric analysis of differentiation in human breast carcinoma. Arch Pathol Lab Med 1983;107:406-10.

8 Zajdela A, Saravia dela Riva L, Ghossein NA. The relation of prognosis to the nuclear diameter of breast cancer cells obtained by cytologic aspiration. Acta Cytol 1979;23:75-80.

9 Baak JPA, Snoo-Nieuwlaat de AJR, Graef de S, Makkink B, Boon M. Prognostic indicators in breast cancermorphometric methods. Histopathology 1982;6:327-39.

10 Knight WA, Livingstone RB, Gregory EJ, McGuire WL.
Estrogen receptors as an independent prognostic factor for early recurrence in breast cancer. Cancer Res 1977;37:4669.

11 Hahnel R. Steroid receptor status, tumour growth and prognosis. In: Stoll BA, ed. Endocrine relations in hreast cancer. Vol 5. London: Heineman, 1982:107-43.

12 Hilf R, Feldstein ML, Gibson SL, Savlov ED. The relative importance of estrogen receptor analysis as a prognostic factor for recurrence or response to chemotherapy in women with breast cancer. Cancer 1980;45:1993-2000.

13 Alanko A, Heinomen E, Scheinin TM, Tolppanen EM, Vihko R. Oestrogen and progesteron receptors and disease-free interval in primary breast cancer. $B r J$ Cancer 1984;50:667-72.

14 Howat JMT, Barnes DM, Harris M, Swindell R. The association of estrogen and progesterone receptors with histological features of breast cancer and early recurrence of disease. $\mathrm{Br} \mathrm{J}$ Cancer 1983;47:629-40.

15 Baak JPA, Dop van H, Kurver PHJ, Hermans J. The value of morphometry to classical prognosticators in breast cancer. Cancer 1985;56:374-82.

16 Azzopardi JG, Chepick OF, Hartmann WH, et al. The WHO histological typing of breast tumors-second edition. Am J Clin Pathol 1982;78:806-16.

17 Nemoto K, Vana J, Bedwani RN, Baker HW, McGregor FH, Murphy GP. Management and survival of female breast cancer: results of a national survey by the American college of surgeons. Cancer 1980;45:2917-24.

18 Lythgoe JP, Leck I, Swindell R. Manchester regional breast study: preliminary results. Lancet 1978;i:744-77.

19 WHO. Handbook for reporting results of cancer treatment. Geneva: World Health Organization, 1979:28-30.

20 Weibel ER. Stereological methods. Vol 1. Practical methods for biological morphometry. London: Academic Press, 1979.

21 Aherne WA, Dunnill MS. Morphometry. London: Edward Arnold, 1982.

22 Oberholzer M. Morphometrie in der klinischen pathologie. Berlin: Springer Verlag, 1983.

23 Baak JPA, Oort J. A Manual of morphometry in diagnostic pathology. Berlin: Springer, 1983.

24 Baak JPA, Persijn JP. In search for the best qualitative microscopical or morphometrical predictor of estrogen receptor in breast cancer. Path Res Pract 1983;187:307-14.

25 Linden JC, Baak JPA, Smeulders AWM, Lindeman J, Meyer CJLM. Morphometry of breast cancer: I. Comparison of the primary tumors and the axillary lymph node metastases. Path Res Pract 1986;181:236-42.

26 Linden JC, Baak JPA, Lindeman J, Meyer CJLM. Morphometry and breast cancer: II. Characterization of breast cancer cells with high malignant potential in lymph node positive patients. A prospective study. J Clin Pathol 1986;39:608-9.

27 EORTC Breast Cancer Cooperative Group. Revision for the assessment of hormone receptors in human breast cancer. Report of the second EORTC workshop, held on 16-17 March 1979, in The Netherlands Cancer Institute. Europ J Cancer 1980;16:1513-5.

28 Dixon WJ, Brown MB, Engelman L, et al. BMDP statistical software. Berkeley: University of California Press, 1983.

Requests for reprints to: Professor JPA Baak, Pathological Institute, Free University Hospital, de Boelelaan 1117, 1007 MB Amsterdam, The Netherlands. 